\title{
Increased Bone Mineral Density with Monthly Intravenous Ibandronate Contributes to Fracture Risk Reduction in Patients with Primary Osteoporosis: Three-Year Analysis of the MOVER Study
}

\author{
Hiroshi Hagino $\cdot$ Seitaro Yoshida $\cdot$ Junko Hashimoto $\cdot$ \\ Masayuki Matsunaga $\cdot$ Masato Tobinai $\cdot$ \\ Toshitaka Nakamura
}

Received: 7 September 2014 / Accepted: 24 October 2014/Published online: 7 November 2014

(C) The Author(s) 2014. This article is published with open access at Springerlink.com

\begin{abstract}
The relationship between gains in bone mineral density (BMD) in the hip and the incidence of vertebral fractures in the MOVER study was examined. Japanese patients from the ibandronate and risedronate treatment groups whose hip BMD had increased during the 3-year treatment period were classified into those with or without vertebral fractures. In both the ibandronate group and the risedronate group, hip BMD gains in the patients who had developed no vertebral fractures during the treatment period were greater than in the patients who developed vertebral fractures. We categorized the gains in hip BMD at 6 months into 3 groups $(\leq 0,>0$ to $\leq 3$, and $>3 \%)$, and used logistic regression analysis to estimate odds ratios and the probabilities of incidence of vertebral fractures at 12 , 24 , and 36 months. The current study demonstrated that greater gains in hip BMD during the first 6 months of treatment were associated with a reduction in the risk of
\end{abstract}

\footnotetext{
H. Hagino $(\square)$

School of Health Science \& Rehabilitation Division, Tottori University Faculty of Medicine, Tottori, Japan

e-mail: hagino@med.tottori-u.ac.jp

S. Yoshida $\cdot$ M. Tobinai

Clinical Development Division, Chugai Pharmaceutical Co. Ltd., Tokyo, Japan

J. Hashimoto

Project \& Lifecycle Management Unit, Chugai Pharmaceutical

Co. Ltd., Tokyo, Japan

M. Matsunaga

Medical Affairs Division, Chugai Pharmaceutical Co. Ltd.,

Tokyo, Japan

T. Nakamura

National Center for Global Health and Medicine, Tokyo, Japan
}

subsequent vertebral fractures during the duration of treatment, and suggested that measurement of hip BMD gain at that time could lead to a prediction of the risk of the future vertebral fracture incidence.

Keywords Ibandronate $\cdot$ Vertebral fracture $\cdot$ Hip BMD change $\cdot$ Osteoporosis $\cdot$ MOVER study

\section{Introduction}

In the treatment of osteoporosis, bisphosphonates have demonstrated their clinical efficacy, particularly their antifracture efficacy, and have become the most widely used anti-osteoporotic drugs worldwide. The anti-fracture efficacy of ibandronate was first demonstrated in the BONE study (oral iBandronate Osteoporosis vertebral fracture trial in North America and Europe) that examined treatment with oral ibandronate $(2.5 \mathrm{mg} /$ day and $20 \mathrm{mg}$ intermittently) [1]. The MOBILE study (Monthly Oral iBandronate In LadiEs) was conducted to assess gains in bone mineral density (BMD) with oral ibandronate (100 and $150 \mathrm{mg} / \mathrm{month}$ ) [2]. The DIVA study (Dosing IntraVenous Administration) was also conducted to assess gains in BMD with quarterly intravenous (IV) ibandronate injection (3 mg/3 months) [3]. Analysis of pooled data from the MOBILE and DIVA trials showed that, for all clinical fractures, non-vertebral fractures, and clinical vertebral fractures, there was a significantly longer time to fracture events in the ibandronate group than in the placebo group over 5 years [4]. Meta-analyses of the clinical studies also demonstrated that ibandronate had significant efficacy with respect to the risk reduction of not only key non-vertebral fractures but also of all non-vertebral fractures and clinical fractures $[5,6]$. 
Table 1 Baseline patient characteristics
$B A L P$ bone-specific alkaline phosphatase, $B C E$ bovine collagen equivalent, $B M D$ bone mineral density, $C R$ creatinine, $S D$ standard deviation, $u C T X$ creatinine-corrected urinary collagen type 1 cross-linked C-telopeptide, $u N T X$ creatininecorrected urinary collagen type 1 cross-linked $\mathrm{N}$-telopeptide

\begin{tabular}{lccr}
\hline & $\begin{array}{l}\text { Ibandronate } 0.5 \mathrm{mg} \\
(n=376)\end{array}$ & $\begin{array}{l}\text { Ibandronate } 1 \mathrm{mg} \\
(n=382)\end{array}$ & $\begin{array}{l}\text { Risedronate } \\
(n=376)\end{array}$ \\
\hline Women, $n(\%)$ & $356(94.7)$ & $354(92.7)$ & $343(91.2)$ \\
Mean age, years (SD) & $72.9(6.34)$ & $72.2(6.38)$ & $73.0(6.29)$ \\
Aged 60-74 years, $n(\%)$ & $219(58.2)$ & $245(64.1)$ & $227(60.4)$ \\
Aged $\geq 75$ years, $n(\%)$ & $157(41.8)$ & $137(35.9)$ & $149(39.6)$ \\
Mean weight, kg (SD) & $50.6(8.00)$ & $50.9(7.36)$ & $51.1(8.35)$ \\
Mean height, cm (SD) & $149.2(6.66)$ & $149.5(6.56)$ & $149.4(6.70)$ \\
Mean BMD T-score (SD) & & & $-2.59(1.06)$ \\
Lumbar spine (L2-L4) & $-2.71(1.01)$ & $-2.68(1.01)$ & $-2.53(0.79)$ \\
Femoral neck & $-2.48(0.73)$ & $-2.41(0.80)$ & $-2.18(0.86)$ \\
Total hip & $-2.17(0.87)$ & $-2.09(0.86)$ & $183(48.7)$ \\
Prevalent vertebral fractures, $n(\%)$ & & & $95(25.3)$ \\
1 & $186(49.5)$ & $184(48.2)$ & $98(26.1)$ \\
2 & $97(25.8)$ & $92(24.1)$ & $373.2(261.0)$ \\
$>2$ & $93(24.7)$ & $368.6(209.9)$ & $68.9(35.16)$ \\
Mean uCTX, $\mu$ g/mmol CR & $382.4(226.2)$ & $69.4(35.42)$ & $32.4(11.96)$ \\
(SD) & & $33.9(13.11)$ & $19.7(6.56)$ \\
Mean uNTX, nM BCE/mM CR & $73.6(39.31)$ & $20.0(6.69)$ & \\
(SD) & $33.6(13.15)$ & & \\
Mean BALP, IU/L (SD) & $19.6(6.44)$ & & \\
Mean 25-OH vitamin D, & & & \\
ng/mL (SD) & & & \\
\hline
\end{tabular}

The relationship between increases in BMD and fracture risk reduction has been examined in meta-analyses of ibandronate. The increase in BMD in the lumbar spine over 2 years showed a reverse relationship with the incidence of clinical fractures, and the increase in hip BMD was associated with a reduction in the risk of non-vertebral fractures [7]. Gains in hip and lumbar spine BMD were also associated with a reduction in vertebral fracture risk, explaining a substantial proportion of the anti-fracture effect of ibandronate (23-37\% at 2 and 3 years) [8]. In fact, it has been reported elsewhere that decreased BMD is strongly associated with increased fracture risks and that increased BMD is predictive of the anti-fracture efficacy of treatment [9].

The MOVER study (MOnthly intraVenous ibandronatE versus daily oral Risedronate) was conducted for registration purposes in Japan [10]. The primary endpoint was the non-inferiority of ibandronate versus risedronate to prove its efficacy with respect to the incidence of non-traumatic vertebral fractures at 3 years. Since the anti-fracture efficacy of risedronate had been already demonstrated in randomized comparative studies [11-13], risedronate was selected as a suitable active comparator in the MOVER study. The incidence rate of first new or worsening vertebral fractures was $16.1 \%$ in the IV ibandronate $1 \mathrm{mg} /$ month treatment group and $17.6 \%$ in the oral risedronate $2.5 \mathrm{mg} /$ day treatment group at 3 years. The hazard ratio of
IV ibandronate $1 \mathrm{mg}$ against risedronate was $0.88(95 \%$ confidence interval [CI] 0.61-1.27). Significant increases in BMD were observed in ibandronate $1 \mathrm{mg}$ group as compared to the risedronate group. Based on the efficacy and safety data, monthly IV ibandronate $1 \mathrm{mg}$ was approved for the treatment of osteoporosis in Japan. The current analysis from the MOVER study was conducted to examine the relationship between changes in hip BMD and the incidence of vertebral fractures, especially the impact that initial BMD gains have on the future incidence of vertebral fractures.

\section{Materials and Methods}

The design of the MOVER study is already described [10]. Briefly, 1,265 patients with primary osteoporosis diagnosed according to the Diagnosis Criteria of Primary Osteoporosis in Japan [14] were randomized. The per-protocol population for the endpoint analysis comprised 376 patients in the ibandronate $0.5 \mathrm{mg}$ group, 382 in the ibandronate $1 \mathrm{mg}$ group, and 376 in the risedronate group (totally 1,134 patients). Baseline patient characteristics were well balanced between the treatment groups (Table 1). Morphometric vertebral fractures were assessed using semiquantitative methodology and quantitative morphometry by a central committee. BMD in lumbar 
spine (L2-L4) and total hip was centrally measured at baseline, 6, 12, 24, and 36 months using dual-energy X-ray absorptiometry (DXA) of Hologic and Lunar bone densitometers. In the current study, the patients in the ibandronate $1 \mathrm{mg}$ group and the risedronate group were sorted by whether or not they developed vertebral fractures over the 3 years of treatment. The increase in BMD in the hip during the treatment period was examined to characterize its correlation with the anti-vertebral fracture efficacy of the drugs. Estimation of odds ratios and probabilities of developing vertebral fractures were performed based on logistic regression analysis. A separate logistic regression analysis was conducted for each of the treatment groups, and the dependent variable was the occurrence of fractures (with fractures) or non-occurrence of fractures (without fractures) during each of the treatment periods, while the independent variables included the change in hip BMD at 6 months $(\leq 0,>0$ to $\leq 3$, or $>3 \%)$, number of existing fractures at screening ( 1 vs. $\geq 2$ fractures), age at baseline ( $<75$ vs. $\geq 75$ years), change in adjusted urinary C-telopeptide levels at 6 months, and change in bone-specific alkaline phosphatase levels also at 6 months. Using the estimated regression parameters and the data of the individual subjects considered for the estimation of those parameters, the probability of fractures in each subject was calculated. This analysis was performed using SAS Version 9.2 (SAS Institute Inc., Cary, NC, USA).

\section{Results}

Increase in hip BMD in Patients Without/With Vertebral Fractures

The mean gains in BMD at 6 months relative to baseline in the ibandronate $1 \mathrm{mg}$ and risedronate treatment groups were 1.7 and $1.3 \%$ in the hip and 5.1 and $3.9 \%$ in the lumbar spine, respectively, in the MOVER study [10]. Among patients receiving IV ibandronate $1 \mathrm{mg}$, the mean changes in hip BMD (Fig. 1a) in the group without vertebral fractures were $1.9 \pm 3.2 \%$ (mean $\pm \mathrm{SD})(n=305)$ at 6 months, $2.9 \pm 3.3 \%(n=290)$ at 1 year, $3.6 \pm 3.3 \%(n=265)$ at 2 years, and $3.5 \pm 3.4 \%(n=242)$ at 3 years. Among patients receiving IV ibandronate $1 \mathrm{mg}$, the mean changes in hip BMD in the group with vertebral fractures were $0.7 \pm 4.9 \%(n=48)$ at 6 months, $1.2 \pm 3.7 \%(n=47)$ at 1 year, $1.5 \pm 4.4 \%(n=42)$ at 2 years, and $1.5 \pm 5.0 \%(n=37)$ at 3 years. Among patients receiving oral risedronate $2.5 \mathrm{mg}$, the mean changes in hip BMD (Fig. 1b) in the group without vertebral fractures were $1.5 \pm 3.1 \% \quad(n=290) \quad$ at 6 months, $\quad 2.3 \pm 3.3 \%$ $(n=276)$ at 1 year, $2.3 \pm 3.7 \%(n=251)$ at 2 years, and $2.2 \pm 3.5 \% \quad(n=228) \quad$ at 3 years. Among patients
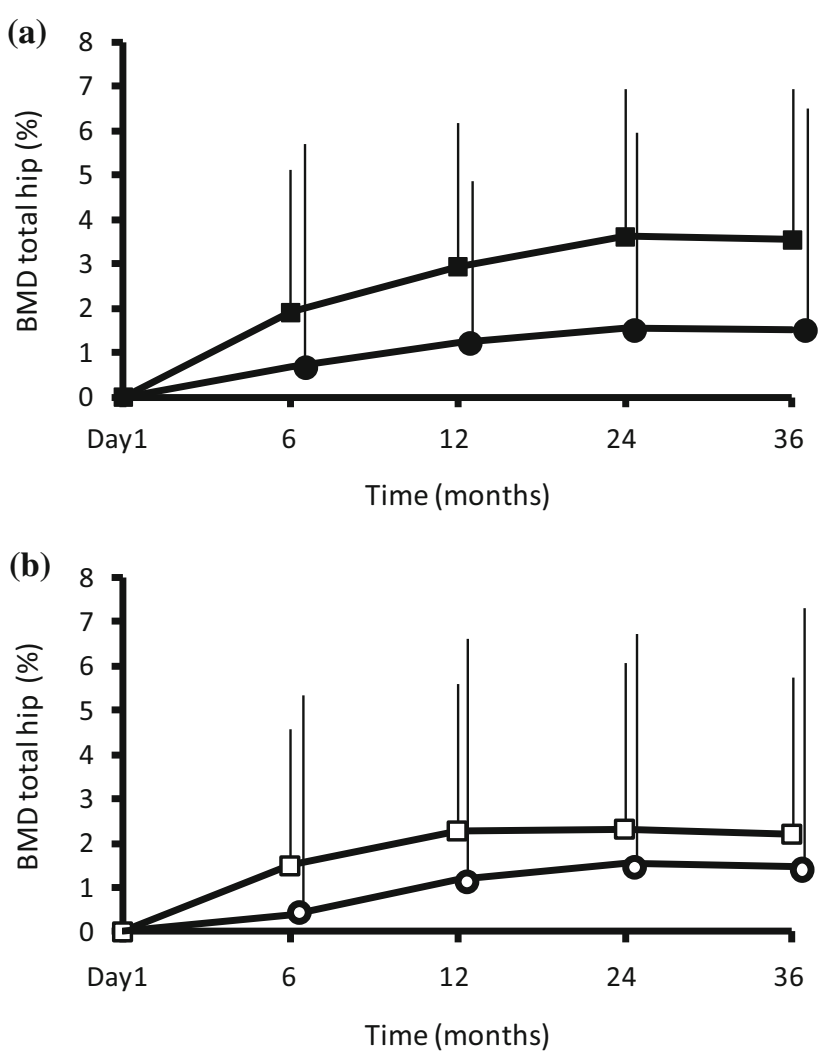

Fig. 1 Mean increases (+SD) in total hip BMD in (a) ibandronatetreated patients with (Black circle) or without (Black square) vertebral fractures; (b) risedronate-treated patients with (White circle) or without (White square) vertebral fractures

receiving oral risedronate $2.5 \mathrm{mg}$, the mean changes in hip BMD in the group with vertebral fractures were $0.4 \pm 4.9 \%(n=60)$ at 6 months, $1.2 \pm 5.4 \%(n=59)$ at 1 year, $1.5 \pm 5.3 \%(n=53)$ at 2 years, and $1.5 \pm 5.9 \%(n=49)$ at 3 years. In both treatment groups, the increases in hip BMD were substantially greater at all measurement times in the groups without vertebral fractures than in the groups with fractures.

Future Vertebral Fracture Incidence Predicted by Changes in Hip BMD at 6 months

The gains in hip BMD at 6 months were categorized into 3 groups $(\leq 0,>0$ to $\leq 3$, and $>3 \%)$. The probability of incidence of vertebral fractures in these 3 groups was estimated at 12, 24, and 36 months (Fig. 2a, ibandronate; Fig. $2 b$, risedronate). In the ibandronate group, the median probabilities of developing vertebral fractures at 12 months in each of the 3 groups were $9.5 \%(n=80), 4.6 \%$ $(n=144)$, and $3.2 \%(n=114)$, respectively. In the risedronate group, the median probabilities of developing vertebral fractures at 12 months were $14.0 \%(n=113)$, $9.2 \%(n=138)$, and $8.2 \%(n=86)$, respectively. The 

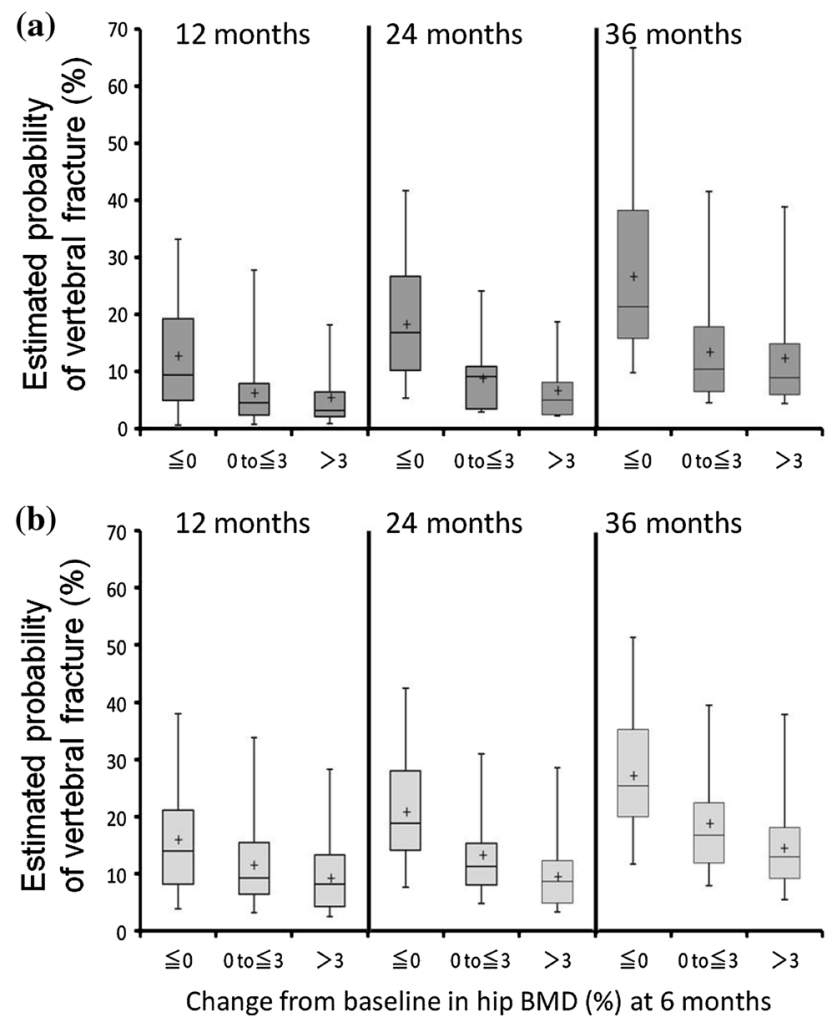

Fig. 2 Estimated probability of incidence of vertebral fractures according to gains in hip BMD in patients treated with ibandronate (a) and risedronate (b) at 12 months (left column), 24 months (middle), and 36 months (right). The upper and lower fences represent the maximum and minimum values, respectively. The box represents the interquartile range. The cross indicates the mean value and the horizontal line indicates the median value

median probabilities of developing vertebral fractures at 24 months were $16.8 \%(n=77), 9.2 \%(n=136)$, and $5.1 \%(n=109)$ in the 3 ibandronate groups and $18.8 \%$ $(n=111), 11.2 \%(n=133)$, and $8.6 \%(n=85)$ in the 3 risedronate groups, respectively. The median probabilities of developing vertebral fractures at 36 months were $21.4 \%(n=72), 10.5 \%(n=128)$, and $8.9 \%(n=102)$ in the 3 ibandronate groups and $25.3 \%(n=100), 16.7 \%$ $(n=119)$, and $13.0 \%(n=78)$ in the 3 risedronate groups, respectively. The numbers of vertebral fracture events that actually occurred (Table 2) were comparable to the probabilities of future vertebral fractures estimated by the logistic regression analysis.

The odds ratios for each group with a positive BMD response ( $>0$ to $\leq 3 \%$ increase from baseline, and $>3 \%$ increase) against the group with inadequate BMD response $(\leq 0 \%)$ were compared for BMD gains in the hip and in the lumbar spine in the first 6 months of treatment (Table 3 ). With respect to the BMD gains in the hip, although the ratios were mostly numerically lower in the ibandronate group than in the risedronate group, it was shown that the
BMD gains in the hip at 6 months promised similarly effective reduction in the risk of future vertebral fracture. The gains in BMD in the femoral neck showed similar trends in reduction of risk of future vertebral fracture (data not shown). With respect to the BMD gains in the lumbar spine at 6 months, the odds ratios were higher in the risedronate group than in the ibandronate group.

\section{Discussion}

The purpose of this analysis of the MOVER study was to examine the relationship between gains in BMD and the occurrence of vertebral fractures by analyzing the gains in hip BMD in the initial 6 months and the subsequent development of vertebral fractures over time.

First, we compared the hip BMD gains in ibandronateor risedronate-treated patients who developed vertebral fractures with those who had not developed vertebral fractures during the 3 years of treatment. In both the ibandronate and the risedronate treatment groups, hip BMD gains were greater in the patients who developed no vertebral fractures during the treatment period than in the patients who developed vertebral fractures. The hip BMD gains in the fracture-negative ibandronate group were consistently greater than in the fracture-negative risedronate group. On the other hand, both fracture-positive groups showed similarly low BMD gains. These results suggested that hip BMD gains could be an effective parameter with which to predict the future incidence of vertebral fractures.

Next, we categorized the patients into 3 groups according to the gains in hip BMD in the first 6 months of treatment, and we used logistic regression analysis to estimate future vertebral fracture risk reduction at 12, 24, and 36 months. Greater gains in hip BMD at 6 months were associated with a greater reduction in the risk of subsequent non-traumatic vertebral fractures over the 3 -year treatment period. The BMD gains in the hip at 6 months, which might be the time-point when the effects of bisphosphonates begin to be seen [15], were shown in our analysis to predict the risk of vertebral fracture incidence. In all treatment periods, the probability of developing vertebral fractures tended to be lower in groups that had hip BMD gains of greater than $3 \%$ than in those that had lesser gains in hip BMD. The numbers of fracture events also decreased according to the gain in BMD. The odds ratios in the hip BMD gains were low overall-under 1 over the 3 years - and the values decreased according to the BMD gains in the both treatment groups. Those results might explain why hip BMD gains might predict the future risk reduction of vertebral fracture. With respect to the BMD gains in the lumbar spine at 6 months, the odds ratios 
Table 2 Numbers of vertebral fracture events according to change in hip BMD at 6 months

\begin{tabular}{|c|c|c|c|c|c|c|}
\hline \multirow{3}{*}{$\begin{array}{l}\text { Treatment } \\
\text { (Months) }\end{array}$} & \multicolumn{3}{|l|}{ Ibandronate } & \multicolumn{3}{|l|}{ Risedronate } \\
\hline & \multicolumn{6}{|c|}{ Hip BMD at 6 months } \\
\hline & $\begin{array}{l}\leq 0 \% \\
(n=85)\end{array}$ & $\begin{array}{l}>0 \text { to } \leq 3 \% \\
(n=150)\end{array}$ & $\begin{array}{l}>3 \% \\
(n=118)\end{array}$ & $\begin{array}{l}\leq 0 \% \\
(n=116)\end{array}$ & $\begin{array}{l}>0 \text { to } \leq 3 \% \\
(n=145)\end{array}$ & $\begin{array}{l}>3 \% \\
(n=89)\end{array}$ \\
\hline 12 & $10(12.5 \%)$ & $9(6.3 \%)$ & $6(5.3 \%)$ & $18(15.9 \%)$ & $16(11.6 \%)$ & $8(9.3 \%)$ \\
\hline 24 & $14(18.2 \%)$ & $12(8.8 \%)$ & $7(6.4 \%)$ & $23(20.7 \%)$ & $17(12.8 \%)$ & $8(9.4 \%)$ \\
\hline 36 & $19(26.4 \%)$ & $17(13.3 \%)$ & $12(11.8 \%)$ & $27(27.0 \%)$ & $22(18.5 \%)$ & $11(14.1 \%)$ \\
\hline \multirow[t]{2}{*}{ Treatment } & \multicolumn{3}{|l|}{ Ibandronate } & \multicolumn{3}{|l|}{ Risedronate } \\
\hline & \multicolumn{6}{|c|}{ Lumbar spine BMD at 6 months ${ }^{\mathrm{a}}$} \\
\hline (Months) & $\begin{array}{l}\leq 0 \% \\
(n=44)\end{array}$ & $\begin{array}{l}>0 \text { to } \leq 3 \% \\
(n=81)\end{array}$ & $\begin{array}{l}>3 \% \\
(n=236)\end{array}$ & $\begin{array}{l}\leq 0 \% \\
(n=61)\end{array}$ & $\begin{array}{l}>0 \text { to } \leq 3 \% \\
(n=100)\end{array}$ & $\begin{array}{l}>3 \% \\
(n=190)\end{array}$ \\
\hline 12 & $3(7.7 \%)$ & $5(6.3 \%)$ & $11(4.8 \%)$ & $3(5.2 \%)$ & $10(10.3 \%)$ & $17(9.3 \%)$ \\
\hline 24 & $5(12.8 \%)$ & $7(9.2 \%)$ & $15(7.0 \%)$ & $5(9.1 \%)$ & $10(10.6 \%)$ & $21(11.7 \%)$ \\
\hline 36 & $6(17.1 \%)$ & $15(22.4 \%)$ & $23(11.2 \%)$ & $5(10.0 \%)$ & $11(12.8 \%)$ & $32(20.3 \%)$ \\
\hline
\end{tabular}

${ }^{a}$ Cases in which vertebral fractures occurred within the first 6 months were eliminated

Table 3 Odds ratios of vertebral fracture incidence at 12, 24, or 36 months according to gains in hip or lumbar spine BMD at 6 months by treatment with ibandronate and risedronate

\begin{tabular}{|c|c|c|c|c|}
\hline \multirow[t]{2}{*}{ Gain in hip BMD at 6 months } & \multirow[t]{2}{*}{ Treatment duration } & \multirow[t]{2}{*}{ Against $\leq 0$} & \multicolumn{2}{|c|}{ Odds ratio $(95 \% \mathrm{CI})$} \\
\hline & & & Ibandronate & Risedronate \\
\hline & \multirow[t]{2}{*}{12 months } & $>0$ to $\leq 3 \%$ & $0.52(0.20,1.41)$ & $0.79(0.37,1.70)$ \\
\hline & & $>3 \%$ & $0.40(0.13,1.21)$ & $0.54(0.22,1.36)$ \\
\hline & \multirow[t]{2}{*}{24 months } & $>0$ to $\leq 3 \%$ & $0.55(0.23,1.31)$ & $0.64(0.32,1.31)$ \\
\hline & & $>3 \%$ & $0.41(0.15,1.14)$ & $0.41(0.17,1.00)$ \\
\hline & \multirow[t]{2}{*}{36 months } & $>0$ to $\leq 3 \%$ & $0.51(0.24,1.09)$ & $0.69(0.35,1.33)$ \\
\hline & & $>3 \%$ & $0.47(0.20,1.09)$ & $0.44(0.20,0.99)$ \\
\hline \multirow[t]{8}{*}{ Gain in lumbar spine BMD at 6 months ${ }^{\mathrm{a}}$} & Treatment duration & Against $\leq 0$ & \multicolumn{2}{|c|}{ Odds ratio $(95 \% \mathrm{CI})$} \\
\hline & & & Ibandronate & Risedronate \\
\hline & \multirow[t]{2}{*}{12 months } & $>0$ to $\leq 3 \%$ & $0.87(0.18,4.16)$ & $2.65(0.67,10.46)$ \\
\hline & & $>3 \%$ & $0.77(0.18,3.21)$ & $2.31(0.62,8.65)$ \\
\hline & \multirow[t]{2}{*}{24 months } & $>0$ to $\leq 3 \%$ & $0.76(0.20,2.79)$ & $1.46(0.46,4.68)$ \\
\hline & & $>3 \%$ & $0.70(0.21,2.29)$ & $1.68(0.57,4.96)$ \\
\hline & \multirow[t]{2}{*}{36 months } & $>0$ to $\leq 3 \%$ & $1.54(0.51,4.63)$ & $1.65(0.52,5.25)$ \\
\hline & & $>3 \%$ & $0.72(0.25,2.03)$ & $3.01(1.05,8.64)$ \\
\hline
\end{tabular}

${ }^{\text {a }}$ Cases in which vertebral fractures occurred within the first 6 months were eliminated

in the risedronate group were higher (but not significantly higher) than in the ibandronate group. It is recently reported that a bisphosphonate which has a lower mineral binding affinity such as ibandronate or risedronate could be efficiently delivered to the cortical bone area. It might be one of explanations that ibandronate showed the greater gains of BMD in the hip in a short period of 6 months [16, 17]. It has been also reported that the changes in lumbar spine BMD by treatment with risedronate contributed only $18 \%$ (95\% CI 10, $26 \%$ ) of its efficacy against vertebral 
fractures [18]. The number of vertebral fracture events in the risedronate group ( $>0$ to $\leq 3$, and $>3 \%$ lumbar spine BMD increase) was greater than in the ibandronate group. Those might be a part of the reasons why the odds ratios in the risedronate group were over 1 . However, further analysis of the individual cases is needed.

Many reports have said that BMD might be a factor predictive of future fractures in general. Additionally, when the BMD measurements of the lumbar spine, femoral neck, femoral trochanter, and hip were compared, hip BMD was reported to be better at predicting future incidence of all fractures than was lumbar spine BMD [19]. BMD measurements in all sites including hip were performed centrally at each time using DXA machine because the MOVER study was a randomized multicenter study. We examined the mean BMD values of each treatment group in the study, however, least significant change or coefficient of variation is important on BMD measurement. In clinical practice, due to variability of hip BMD measurement, there might be a difficulty to obtain the accurate data even though the treatment would express the efficacy at 6 months. The relationship between BMD in the first 6 months and the time-course of incidence of hip fractures should also be investigated; however, we did not get any information due to the low number of non-vertebral fractures including hip that occurred in the MOVER study.

Our analysis did not show the contribution rate of BMD gains to the expression of the anti-fracture efficacy in the MOVER study. It has been reported previously [8] that BMD gains by ibandronate would explain approximately one-third (24-37\%) of ibandronate's anti-fracture efficacy. That contribution rate was derived from analysis of the BONE and IV studies in which the annual cumulative exposure (ACE) was under $5.5 \mathrm{mg}$. However, the ACE in the MOVER study was $12 \mathrm{mg}$; thus, the contribution of BMD gains in the MOVER study might be much bigger. We intend to calculate the contribution of BMD gains in future analysis.

Our current analysis indicated that greater gains of BMD in the hip in a relatively short period of 6 months of treatment were associated with a greater reduction in the risk of future vertebral fracture incidence. In fact, the BMD measurements using DXA machine are reimbursable every 4 month in Japan and the physicians like to measure BMD to evaluate the treatment regimen. We, in Japan, suggest to measure BMD after 6 months of therapy and keep to do every 6 month. In case the BMD measurement is not available or practical, the measurement of bone turnover markers (BTMs) could be supportive. In these days, not only physicians but also patients would discuss their laboratory data including BMD or BTMs values together, which is desirable to keep better adherence to therapy for osteoporosis. If there is no gain in BMD, it is an opportunity to re-assess the current therapy. To change drug would be one of next options and to add another drug would be also an alternative. The results suggest that the hip BMD value at 6-month treatment might be a useful predictor to prevent the future vertebral fracture incidence and provide an opportunity to assess the treatment options.

Acknowledgments All analyses for publication were the responsibility of Chugai Pharmaceutical Co. Ltd. All authors contributed to the manuscript and have approved the final version for submission. The authors acknowledge Dr. Daiva Masanauskaite of F. HoffmannLa Roche Ltd. for discussing the results with them. The MOVER study was founded by Chugai Pharmaceutical Co. Ltd. and Taisho Pharmaceutical Co. Ltd.

Conflict of interest Hiroshi Hagino has received consulting fees from Asahi Kasei Pharma Corp., Astellas Pharma Inc., Banyu Pharmaceutical Co. Ltd., Chugai Pharmaceutical Co. Ltd., Eisai Co. Ltd., Eli Lilly Japan K.K., Mitsubishi Tanabe Pharma Corp., Ono Pharmaceutical Co. Ltd., Pfizer Inc., Takeda Pharmaceutical Co. Ltd., and Teijin Pharma Ltd. Seitaro Yoshida, Junko Hashimoto, Masayuki Matsunaga, and Masato Tobinai are employees of Chugai Pharmaceutical Co. Ltd. Toshitaka Nakamura has received research Grants and/or consulting fees from Asahi Kasei Pharma Corp., Astellas Pharma Inc., Banyu Pharmaceutical Co. Ltd., Chugai Pharmaceutical Co. Ltd., Daiichi Sankyo Inc., Eisai Co. Ltd., Eli Lilly Japan K.K., Ono Pharmaceutical Co. Ltd., Takeda Pharmaceutical Co. Ltd., and Teijin Pharma Ltd., and belongs to the Japan Ministry of Health, Welfare and Labor as a councilor for hospital administration and social medical insurance.

Human and Animal Rights and Informed Consent In accordance with the Declaration of Helsinki and the International Conference on Harmonization of Good Clinical Practice Guidelines. All patients provided written informed consent prior to any study-related procedure.

Open Access This article is distributed under the terms of the Creative Commons Attribution License which permits any use, distribution, and reproduction in any medium, provided the original author(s) and the source are credited.

\section{References}

1. Chesnut CH III, Skag A, Christiansen C, Recker R, Stakkestad JA, Hoiseth A, Felsenberg D, Huss H, Gilbride J, Schimmer RC, Delmas PD, Oral Ibandronate Osteoporosis Vertebral Fracture Trial in North America and Europe (BONE) (2004) Effects of oral ibandronate administered daily or intermittently on fracture risk in postmenopausal osteoporosis. J Bone Miner Res 19:1241-1249

2. Reginster JY, Adami S, Lakatos P, Greenwald M, Stepan JJ, Silverman SL, Christiansen C, Rowell L, Mairon N, Bonvoisin B, Drezner MK, Emkey R, Felsenberg D, Cooper C, Delmas PD, Miller PD (2006) Efficacy and tolerability of once-monthly oral ibandronate in postmenopausal osteoporosis: 2 year results from the MOBILE study. Ann Rheum Dis 65:654-661

3. Eisman JA, Civitelli R, Adami S, Czerwinski E, Recknor C, Prince R, Reginster JY, Zaidi M, Felsenberg D, Hughes C, Mairon N, Masanauskaite D, Reid DM, Delmas PD, Recker RR (2008) Efficacy and tolerability of intravenous ibandronate injections in postmenopausal osteoporosis: 2-year results from the DIVA study. J Rheumatol 35:488-497 
4. Miller PD, Recker RR, Harris S, Silverman S, Felsenberg D, Reginster J, Day DM, Barr C, Masanauskaite D (2014) Longterm fracture rates seen with continued ibandronate treatment: pooled analysis of DIVA and MOBILE long-term extension studies. Osteoporos Int 25:349-357

5. Harris ST, Blumentals WA, Miller PD (2008) Ibandronate and the risk of non-vertebral and clinical fractures in women with postmenopausal osteoporosis: results of a meta-analysis of phase III studies. Curr Med Res Opin 24:237-245

6. Cranney A, Wells GA, Yetisir E, Adami S, Cooper C, Delmas PD, Miller PD, Papapoulos S, Reginster JY, Sambrook PN, Silverman S, Siris E, Adachi JD (2009) Ibandronate for the prevention of nonvertebral fractures: a pooled analysis of individual patient data. Osteoporos Int 20:291-297

7. Sebba AI, Emkey RD, Kohles JD, Sambrook PN (2009) Ibandronate dose response is associated with increases in bone mineral density and reductions in clinical fractures: results of a meta-analysis. Bone 44:423-427

8. Miller PD, Delmas PD, Huss H, Patel KM, Schimmer RC, Adami S, Recker RR (2010) Increases in hip and spine bone mineral density are predictive for vertebral antifracture efficacy with ibandronate. Calcif Tissue Int 87:305-313

9. Berger C, Langsetmo L, Joseph L, Hanley DA, Davison KS, Josse RG, Prior JC, Kreiger N, Tenenhouse A, Goltzman D, CaMos Research Group (2009) Association between change in BMD and fragility fracture in women and men. J Bone Miner Res 24:361-370

10. Nakamura T, Nakano T, Ito M, Hagino H, Hashimoto J, Tobinai M, Mizunuma H, MOVER Study Group (2013) Clinical efficacy on fracture risk and safety of $0.5 \mathrm{mg}$ or $1 \mathrm{mg} / \mathrm{month}$ intravenous ibandronate versus $2.5 \mathrm{mg}$ /day oral risedronate in patients with primary osteoporosis. Calcif Tissue Int 93:137-146

11. Reginster J, Minne HW, Sorensen OH, Hooper M, Roux C, Brandi ML, Lund B, Ethgen D, Pack S, Roumagnac I, Eastell R (2000) Randomized trial of the effects of risedronate on vertebral fractures in women with established postmenopausal osteoporosis. Vertebral Efficacy with Risedronate Therapy (VERT) Study Group. Osteoporos Int 11:83-91

12. McClung MR, Geusens P, Miller PD, Zippel H, Bensen WG, Roux C, Adami S, Fogelman I, Diamond T, Eastell R, Meunier PJ, Reginster JY, Hip Intervention Program Study Group (2001) Effect of risedronate on the risk of hip fracture in elderly women.
Hip Intervention Program Study Group. $\mathrm{N}$ Engl $\mathrm{J}$ Med 344:333-340

13. Harris ST, Watts NB, Genant HK, McKeever CD, Hangartner T, Keller M, Chesnut CH 3rd, Brown J, Eriksen EF, Hoseyni MS, Axelrod DW, Miller PD (1999) Effects of risedronate treatment on vertebral and nonvertebral fractures in women with postmenopausal osteoporosis: a randomized controlled trial. Vertebral Efficacy With Risedronate Therapy (VERT) Study Group. JAMA 282:1344-1352

14. Orimo H, Hayashi Y, Fukunaga M, Sone T, Fujiwara S, Shiraki M, Kushida K, Miyamoto S, Soen S, Nishimura J, Oh-Hashi Y, Hosoi T, Gorai I, Tanaka H, Igai T, Kishimoto H, Osteoporosis Diagnostic Criteria Review Committee: Japanese Society for Bone and Mineral Research (2001) Diagnostic criteria for primary osteoporosis: year 2000 revision. J Bone Miner Metab 19:331-337

15. Roux C, Seeman E, Eastell R, Adachi J, Jackson RD, Felsenberg D, Songcharoen S, Rizzoli R, Ombretta Di Munno OD, Horlait S, Valent D, Watts NB (2004) Efficacy of risedronate on clinical vertebral fractures within six months. Curr Med Res Opin 20:433-439

16. Nancollas GH, Tang R, Phipps RJ, Henneman Z, Gulde S, Wu W, Mangood A, Russell RGG, Ebetino FH (2006) Novel insights into actions of bisphosphonates on bone: differences in interactions with hydroxyapatite. Bone 38:617-627

17. Zebaze RM, Libanati C, Austin M, Ghasem-Zadeh A, Hanley DA, Zanchetta JR, Thomas T, Boutroy S, Bogado C, Bilezikian JP, Seeman E (2014) Differing effects of denosumab and alendronate on cortical and trabecular bone. Bone 59:173-179

18. Watts NB, Cooper C, Lindsay R, Eastell R, Manhart MD, Barton IP, van Staa TP, Adachi JD (2004) Relationship between changes in bone mineral density and vertebral fracture risk associated with risedronate: greater increases in bone mineral density do not relate to greater decreases in fracture risk. J Clin Densitom 7:255-261

19. Leslie WD, Tsang JF, Caetano PA, Lix LM, for the Manitoba Bone Density Program (2007) Effectiveness of bone density measurement for predicting osteoporotic fractures in clinical practice. J Clin Endocrinol Metab 92:77-81 